\title{
THE GEOMETRIC KNEE REPLACEMENT IN POLYARTHRITIS
}

\author{
J. A. HUNTer, A. A. ZOMA, J. E. SCUllion, K. PROTheroe, A. B. YOUNG, R. D. STURROCK, H. A. CAPELl
}

From the Centre for Rheumatic Diseases and Glasgow Royal Infirmary, Glasgow

\begin{abstract}
The British Orthopaedic Association assessment questionnaire for knee replacements was adapted to allow comparison of the severity of underlying polyarthritis with the benefits of geometric knee replacement in a retrospective study of 150 knees between six months and six years after operation. Total or partial relief of pain was achieved in 81 per cent of the operations, and changes in mobility occurred in fewer patients. Late sepsis remained a serious complication of nine per cent of the operations and one patient died from septicaemia. Late sepsis was associated with previous synovectomy or osteotomy. Retropatellar pain rarely interfered with the mobility of the patient.

There was no association of operations that failed with a high erythrocyte sedimentation rate, a high platelet count, a low haemoglobin level or with a strongly positive rheumatoid factor but pain in the contralateral knee was associated with a diminished functional capacity.
\end{abstract}

Although replacement of the knee is not as successful as that of the hip its place in the management of chronic arthritis is established. It seems likely that the ideal knee prosthesis has yet to be designed, as so many alternatives are offered. We have used the geometric knee in the majority of replacements performed during the last six years. Most of the patients requiring operation suffered from chronic polyarthritis. In this retrospective study we have aimed to follow-up the patients with geometric replacements so as to identify the benefits and complications of the operation, and also any avoidable factors detrimental to the management of the patient.

\section{METHODS AND MATERIAL}

Indications for operation. The primary indication for knee replacement was persistent pain unresponsive to available medical therapy. Secondary considerations were the correction of deformity and instability, and the desire to improve the useful arc, though not necessarily the range, of movement. No patient was offered geometric replacement in the presence of gross instability, flexion contracture of more than $\mathbf{4 5}$ degrees, or varus and valgus malalignment greater than 20 degrees. Other contra-indications included gross obesity, severe osteoporosis of surrounding bone, clinical evidence of peripheral vascular disease, previous sepsis in the knee or active infection elsewhere. In patients with significant concomitant disease of the hip or forefoot, surgical attention was initially confined to these areas. Operative and postoperative management. The operating theatre used was conventional in design with filtered air supplied at 10 changes per hour. Its use was restricted to operations on the hip, knee, ankle, foot and hand. Prophylactic cloxacillin (500 milligrams intramuscularly) was given with the anaesthetic premedication, and continued by giving two grams daily for one to two weeks after operation. The operative technique was based on that of Coventry and his colleagues (Coventry et al. 1972; Skolnick, Coventry and Ilstrup 1976). The majority of incisions were paramedian, though recently we have favoured a midline approach. Patellar osteophytes were trimmed. Axial alignment was carried out without a guide. Bony irregularities of the distal end of the femur were removed in order to facilitate smooth patellofemoral movement. After operation the knee was immobilised in a pipestem plaster of Paris cast for one week. The cast was then bivalved and gentle active flexion of the knee started. Sutures were removed after two weeks. In six patients restricted flexion, despite energetic physiotherapy, was overcome by manipulation under anaesthesia two to three weeks after the operation.

Follow-up assessment. One hundred and fifty-four geometric knee replacements in 126 patients were performed in the Centre for Rheumatic Diseases between April 1974 and February 1980 (repeat geometric replacements in the same knee were excluded from this study). Four patients could not be traced, but of the remaining 150 replacements 123 were reviewed at a special clinic, and information on the others was gathered by postal questionnaires sent to the patients and their general practitioners. Twelve patients had died and information about them was sought from the general practitioner and primary care or hospital records. In all cases, additional and corroborative data were gathered from the records at the Centre for Rheumatic Diseases.

Radiographs of arthritic knees were assessed using Larsen's method (Larsen and Dale 1979). Where possible information from the case notes concerning delayed healing (an open wound for at least 12 days after operation), infection, deep-vein thrombosis, pulmonary embolism and retropatellar pain was specifically recorded. Statistical methods employed were non-parametric throughout (Siegel 1956).

The age of the patients at the time of operation ranged from 28 to 79 years (mean 60 years), and the sex ratio was $1: 4.4$ (male :female). Ninety per cent suffered from classical or definite rheumatoid arthritis (Ropes 1959), eight per cent from osteoarthritis, and three knee replacements were performed in patients suffering from seronegative disease. The minimum period of follow-up was six months with a mean of three years.

\footnotetext{
J. A. Hunter, MRCP, Honorary Senior Registrar

A. A. Zoma, MRCP, Registrar

R. D. Sturrock, MRCP, Senior Lecturer and Consultant H. A. Capell, MRCP, Consultant Physician

K. Protheroe, FRCS, Consultant Orthopaedic Surgeon

A. B. Young, FRCS, Consultant Orthopaedic Surgeon

J. E. Scullion, FRCS, Senior Orthopaedic Registrar, Aberdeen Royal Infirmary, Foresterhill, Aberdeen AB9 8AU, Scotland.

Requests for reprints should be sent to $\mathrm{Dr}$ J. A. Hunter.

() 1982 British Editorial Society of Bone and Joint Surgery 0301-620X/82/1022-0095 \$2.00

Centre for Rheumatic Diseases,

35 Baird Street, Glasgow G4 OEH, Scotland.

Centre for Orthopaedic Surgery,

Centre for Orthopaedic Surgery,
}

VOL $64-1$, No, 1,1982 
Table I. Subjective benefits of knee replacement

\begin{tabular}{|l|c|c|c|}
\hline & $\begin{array}{c}\text { Better } \\
(\text { per cent) }\end{array}$ & $\begin{array}{c}\text { No change } \\
(\text { per cent) }\end{array}$ & $\begin{array}{c}\text { Worse } \\
(\text { per cent })\end{array}$ \\
\hline Pain in operated joint & 81 & 2 & 6 \\
Walking tolerance & 50 & 32 & 9 \\
Use of walking aids & 34 & 43 & 14 \\
Ability to climb stairs & 44 & 41 & 4 \\
\hline
\end{tabular}

* Percentage of operations.

\section{RESULTS}

Table I shows the subjective benefits of geometric knee replacement. Only 12 patients felt that the replacement left the knee unchanged or made it worse. These operations failed to relieve pain in nine cases and the remainder developed late sepsis at least three months after operation. The need for a second operation, instability or immobility after operation contributed to patient dissatisfaction in 50 per cent, 14 per cent and 71 per cent of cases respectively. Nevertheless, 81 per cent of the replacements relieved pain in the knee and in 58 per cent of the patients there was no pain at follow-up. This corresponded with the 75 per cent who felt that the result of the operation was excellent or good and the 79 per cent who would have the operation again if required.

Changes in mobility were less marked than relief of pain. Although only nine per cent of the replacements showed a diminished tolerance to walking after operation, in a further 32 per cent it was unchanged. Similar results were obtained regarding the use of walking aids and the ability to climb stairs. As most of our patients suffered from polyarthritis, it is likely that other joints contributed to their disability. For instance, there was a significant association $(P<0.05)$ between pain in the contralateral knee and both walking tolerance and the use of walking aids. Only five patients were unable to walk at follow-up. This accounted for seven operations; one patient with bilateral replacements suffered from psoriatic arthritis and spondylitis, and the other had advanced destructive rheumatoid arthritis complicated by significant gastrointestinal and cardiorespiratory problems. Both these patients had difficulty with rehabilitation after operation. In two other patients, trauma and vertigo led to confinement in a chair and in one remaining patient there was no identifiable cause.

Comparison of the range of movement before and after operation showed no evidence of change in the 70 patients where complete information was available. Useful movement was defined by at least 50 degrees of flexion and was present in 83 per cent. At follow-up six per cent of the knees were complicated by varus deformity and 12 per cent were in more than 12 degrees of valgus. Twenty-seven per cent had a flexion contracture of more than 10 degrees and 69 per cent had less than 10 degrees. Instability was present in two knees
Table II. Failures of geometric replacements caused by late sepsis

\begin{tabular}{|l|c|c|c|}
\hline & $\begin{array}{r}\text { Patients } \\
\text { with late } \\
\text { sepsis }\end{array}$ & Others & Significance \\
\hline Number of knees & 14 & 136 & \\
$\begin{array}{l}\text { Previous operations to } \\
\text { involved knee }\end{array}$ & 9 & 28 & $P<0.01$ \\
$\quad$ synovectomy & 6 & 15 & $P<0.01$ \\
$\quad$ osteotomy & 3 & 5 & - \\
Patients who received & & & \\
steroids or ACTH & 4 & 47 & NS \\
systemically & 4 & 15 & NS \\
to involved knee & 10 & 16 & $P<0.001$ \\
Patients with delayed healing & 1 & - & \\
$\quad$ septicaemic deaths & 4 & - & \\
repeat replacement & 4 & - & \\
arthrodesis & 3 & - & \\
settled with medical therapy & 1 & - & \\
chronic recurrent discharge & &
\end{tabular}

and was responsible for repeat geometric replacement in two others.

Follow-up radiographs were obtained for 122 knee replacements. Although a lucent line was identified at the bone-cement interface below the tibial component in $36 \mathrm{knees,}$ this finding was not associated with more severe symptoms. Radiological follow-up revealed loosening of the tibial component and in one patient this was subsequently confirmed at operation. One patient with loosening was asymptomatic. In two cases of varus malalignment, there was a fracture of the medial tibial condyle. One of these patients was suffering pain at rest, but the other was asymptomatic.

Other than poor symptomatic response, failure of the geometric replacement was judged to have occurred when late sepsis complicated the procedure (Table II) or when a further operation was needed (Table III). Patients who developed late sepsis after geometric replacement had more frequently received a previous operation to that knee $(P<0.01)$. In two patients the preceding operation did not involve entry into the joint (high tibial osteotomy), but even when these were excluded there was still a significantly higher proportion of patients with a history of more than one operation to the knee when the geometric prosthesis was complicated by late sepsis $(P<0.01)$. Although more patients developing late sepsis had been given a steroid injection into the operated knee before operation this difference failed to reach statistical significance. Thirty-eight per cent of the patients with delayed healing developed late sepsis and the isolation of similar organisms in early and late sepsis (Table IV) confirms the significance of this association. 
Table III. Knees requiring second operations

\begin{tabular}{|c|c|c|c|}
\hline Indication & $\begin{array}{l}\text { Number of } \\
\text { patients }\end{array}$ & $\begin{array}{c}\text { Operation } \\
\text { (number of patients) }\end{array}$ & Result \\
\hline Late sepsis & 8 & $\begin{array}{l}\text { Repeat replacement (4) } \\
\text { Arthrodesis }\end{array}$ & $\begin{array}{l}3 \text { Successful } \\
1 \text { Housebound } \\
1 \text { Continued sepsis } \\
3 \text { Housebound }\end{array}$ \\
\hline Instability & 2 & Repeat replacement & $\begin{array}{l}1 \text { Chairbound } \\
1 \text { Housebound }\end{array}$ \\
\hline Infected after injury & 1 & Arthrodesis & Housebound \\
\hline Trauma and retropatellar pain & 1 & Arthrodesis & $\begin{array}{l}\text { Decreased } \\
\text { mobility }\end{array}$ \\
\hline
\end{tabular}

Table IV. Organisms cultured after geometric replacement

\begin{tabular}{|l|c|c|}
\hline & $\begin{array}{c}\text { Delayed healing } \\
n=26 \text { knees }\end{array}$ & $\begin{array}{c}\text { Late sepsis } \\
n=14 \text { knees }\end{array}$ \\
\hline Staphylococcus aureus & 16 & 8 \\
Staphylococcus epidermidis & 3 & 2 \\
Streptococcus faecalis & 1 & 1 \\
Escherichia coli & 2 & 2 \\
Enterobacter cloacae & 2 & 1 \\
Gram-positive bacilli & 1 & - \\
No growth & 6 & 3 \\
No cultures & - & 1 \\
\hline
\end{tabular}

Table V. Minor complications

\begin{tabular}{|l|c|c|}
\hline & $\begin{array}{c}\text { Number of } \\
\text { knees }\end{array}$ & $\begin{array}{c}\text { Percentage of } \\
\text { operations }\end{array}$ \\
\hline Anaemia after operation: & 51 & 34 \\
haemoglobin $>2 \mathrm{~g} / 100 \mathrm{ml}$ & 64 & 43 \\
$\quad$ transfused & 26 & 17 \\
Delayed healing & 10 & 7 \\
$\begin{array}{l}\text { Delayed healing complicated } \\
\text { by late sepsis }\end{array}$ & 2 & - \\
$\begin{array}{l}\text { Acute renal insufficiency } \\
\text { Severe sepsis of sacral nodule }\end{array}$ & 1 & - \\
\hline
\end{tabular}

All cases of late sepsis occurred in patients suffering from rheumatoid disease, but there was no evidence from the frequency of visits to the clinic, from the erythrocyte sedimentation rates, or from the haemoglobin levels or rheumatoid factor titres, that patients developing late sepsis suffered more severe disease. In one patient late sepsis resulted in septicaemia and death. This patient presented suddenly five months after knee replacement and six months after total hip replacement with a five-day-history of pain in both hips. Investigations revealed multiple infections of the joints and at necropsy both knees contained pus. No other complication of geometric replacement occurred and it is our impression that some other unidentified focus was responsible for her staphylococcal septicaemia. Two other patients who developed late sepsis have died from unrelated causes. Three patients were treated by conservative measures usually requiring intermittent courses of antibiotics. The knees continue to discharge non-purulent material in two patients. Four knees with late sepsis were subjected to repeat geometric replacement using cement impregnated with gentamicin, and another four to arthrodesis. After a maximum of nine months follow-up, three repeat replacements had been successful. One of the four arthrodeses was complicated by recurrent infection in the operated knee and is now being controlled by long-term antibiotic therapy. One patient developed sepsis around the geometric prosthesis after a closed subprosthetic tibial fracture. Sepsis was controlled but the fracture failed to heal and an arthrodesis was performed with success. The remaining repeat geometric replacements were performed for instability (two knees). Retropatellar pain (in the absence of late sepsis) was sufficiently severe to interfere with mobility in only one of the five patients affected by this complication.

Other less serious complications ( Table V) included anaemia after operation, acute renal insufficiency and severe sepsis in a sacral nodule which was partially attributable to immobility after operation. The haemoglobin change and the units of blood transfused were not significantly different between patients with rheumatoid arthritis and those with osteoarthritis. Renal insufficiency after operation recovered with conservative management and did not require dialysis. Twelve patients had died since geometric replacement, but in only one was death related to the operation; one patient died from pulmonary thromboembolism which occurred 18 months after insertion of the prosthesis. The other deaths were unrelated to arthritis or its treatment.

\section{DISCUSSION}

The difficulty of assessing knee prostheses has received recent attention (Lettin 1980). In view of the need to assess the complications as well as the relief of pain and 
functional improvement, we modified the British Orthopaedic Association questionnaire (Aichroth et al. 1978). In addition, the use of arbitrary criteria for assessing the severity of the disease has allowed a comparison with the eventual success of the geometric prosthesis. Although there was an expected excess of hospital admissions for arthritis, we have found no evidence that more active rheumatoid disease is related to the development of late sepsis. This was contrary to our original hypothesis and suggests that a more detailed prospective study should be performed, particularly when so much evidence exists for predisposition to infection in rheumatoid disease.

The results of geometric knee replacement in this survey demonstrate the benefits resulting from the operation. Late sepsis, especially in patients with rheumatoid arthritis (Petty et al. 1975; Wilson et al. 1980), remains the most important hazard. Previous operations increased the risk of developing late sepsis; this is consistent with observations in total hip replacement where micro-organisms have been isolated from incisions at operation (Fitzgerald et al. 1973; Fitzgerald and Washington 1975). The higher incidence of previous operations in patients who developed late sepsis complicating geometric replacement indicates the need to assess possible long-term advantages of medical synovectomy (for example, with intra-articular radioisotopes) as an alternative to other surgical procedures in early knee disease. Although statistical significance was not established, the large number of patients receiving intra-articular steroids before operation suggests a further reason why these drugs should not form a major part of therapy in rheumatoid disease.

Since this study was carried out, the policy in our unit concerning antibiotic prophylaxis has changed and we now favour shorter courses of flucloxacillin. Since the safety of cement impregnated with gentamicin is established this may also confer advantages in rheumatoid patients.

Patellofemoral arthritis appears to be an insignificant problem in our series, and spontaneous complaints referring to this disease led to a repeat operation with an unsuccessful result in only one patient. This patient had also fractured her tibia between operations and at this late date it is uncertain how her trauma related to the retropatellar pain. In one other patient mild functional disability was associated with retropatellar pain. The rarity of this complication in rheumatoid disease has been described before (Wilson, Fajgenbaum and Venters 1980) and suggests that it is an inappropriate reason to withhold the geometric prosthesis from patients who otherwise need replacement. Although the disadvantages of retrospective surveys are recognised, we conclude that geometric knee replacement remains a useful procedure in the relief of pain for advanced rheumatoid arthritis in the knee. Further refinements for the operation and the accumulation of experience may increase the benefits of the replacements.

We are grateful to Mrs M. Tucker who typed the manuscript. John Hunter is supported by the Arthritis and Rheumatism Council.

\section{REFERENCES}

Aichroth P, Freeman MAR, Smillie IS, Souter WA. A knee function assessment chart. J Bone Joint Surg [Br] 1978;60-B:308-9.

Coventry MB, Finerman GAM, Riley LH, Turner RH, Upshaw JE. A new geometric knee for total knee arthroplasty. Clin Orthop $1972 ; 83: 157-62$.

Fitzgerald RH Jr, Peterson LFA, Washington JA II, Van Scoy RE, Coventry MB. Bacterial colonization of wounds and sepsis in total hip arthroplasty. J Bone Joint Surg [Am] 1973;55-A:1242-50.

Fitzgerald RH Jr, Washington JA II. Contamination of the operative wound. Orthop Clin North Am 1975;6:1105-14.

Larsen A, Dale K. Standardized radiological evaluation of rheumatoid arthritis. In: Dumonde DC, Stewart MW, eds. Laboratory tests in rheumatic diseases. Lancaster: MTP Press, 1979:59-70.

Lettin AWF. Total joint replacement. Br J Hosp Med 1980;24:328-34.

Petty W, Bryan RS, Coventry MB, Peterson LFA. Infection after total knee arthroplasty. Orthop Clin North Am 1975;6:1005-14.

Ropes MW, Chairman. Committee of the American Rheumatism Association. Diagnostic criteria for rheumatoid arthritis. 1958 revision. Ann Rheum Dis 1959;18:49-53.

Siegel S. Nonparametric statistics for the behavioral sciences. New York: McGraw-Hill, 1956.

Skolnick MD, Coventry MB, Ilstrup DM. Geometric total knee arthroplasty. J Bone Joint Surg [Am] 1976;58-A:749-53.

Wilson FC, Fajgenbaum DN, Venters GC. Results of knee replacements with the Walldius and geometric prostheses. J Bone Joint Surg [Am] 1980;62-A:497-503. 